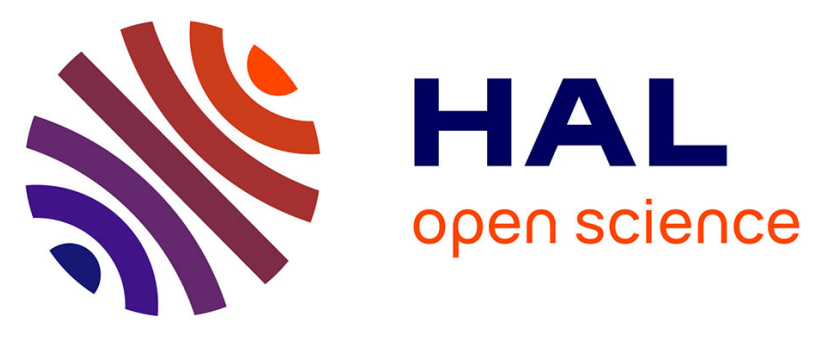

\title{
Improved adhesion of polycrystalline diamond films on copper/carbon composite surfaces due to in situ formation of mechanical gripping sites
}

Clio Azina, Mengmeng Wang, Emilien Feuillet, Loic Constantin, Bruno

Mortaigne, Pierre-Marie Geffroy, Yongfeng Lu, Jean-François Silvain

\section{To cite this version:}

Clio Azina, Mengmeng Wang, Emilien Feuillet, Loic Constantin, Bruno Mortaigne, et al.. Improved adhesion of polycrystalline diamond films on copper/carbon composite surfaces due to in situ formation of mechanical gripping sites. Surface and Coatings Technology, 2017, 321, pp.1-7. 10.1016/j.surfcoat.2017.04.037 . hal-01531340

\author{
HAL Id: hal-01531340 \\ https://hal.science/hal-01531340
}

Submitted on 1 Jun 2017

HAL is a multi-disciplinary open access archive for the deposit and dissemination of scientific research documents, whether they are published or not. The documents may come from teaching and research institutions in France or abroad, or from public or private research centers.
L'archive ouverte pluridisciplinaire HAL, est destinée au dépôt et à la diffusion de documents scientifiques de niveau recherche, publiés ou non, émanant des établissements d'enseignement et de recherche français ou étrangers, des laboratoires publics ou privés. 


\title{
Improved Adhesion of Polycrystalline Diamond Films on Copper/Carbon Composite surfaces due to in situ formation of mechanical gripping sites
}

C. Azina ${ }^{1,2}$, M.M. Wang ${ }^{2}$, E. Feuillet ${ }^{1}$, L. Constantin ${ }^{1,2}$, B. Mortaigne $^{3}$, P.-M. Geffroy ${ }^{4}$, Y.F. $\mathrm{Lu}^{2}, \mathrm{~J}-\mathrm{F}$. Silvain ${ }^{1,2}$

${ }^{1}$ CNRS, Univ. Bordeaux, ICMCB, UPR 9048, F-33600 Pessac, France

${ }^{2}$ Department of Electrical and Computer Engineering, University of Nebraska-Lincoln, Lincoln, Nebraska 68588-0511, United States

${ }^{3}$ DGA/DS/Mission pour la Recherche et l'Innovation Scientifique, 92221 Bagneux, France

${ }^{4}$ CNRS, Univ. Limoges, ENSCI, SPCTS, UMR 7531, 87065 Limoges, France

\begin{abstract}
Diamond coatings are investigated for thermal management, wear protection and corrosion resistance in harsh environments. In power electronic industries, copper $(\mathrm{Cu})$, which shows high thermal conductivity, is considered as a promising substrate for diamond based heat-spread materials. However, the coefficient of thermal expansion (CTE) mismatch between diamond and $\mathrm{Cu}$ induces thermo-mechanical stresses that affect the integrity of the diamond-Cu assembly. In fact, diamond films deposited on $\mathrm{Cu}$ substrates tend to peel-off upon cooling due to the compressive stresses present at the diamond-Cu interface. This investigation is focused on the growth of polycrystalline diamond thin films onto $\mathrm{Cu} / \mathrm{CF}$ (CF) composite materials, using combustion flame chemical vapor deposition (CVD). It has been found that increased $\mathrm{CF}$ content in the $\mathrm{Cu} / \mathrm{CF}$ materials leads to a reduced CTE improving, hence, the adhesion between the diamond film and the $\mathrm{Cu} / \mathrm{CF}$ substrate and reduces $\mathrm{Cu} / \mathrm{CF}$-diamond interfacial residual thermal stresses. At a CF content of $40 \%$ in volume, the residual thermal stress of the diamond film deposited on the $\mathrm{Cu} / \mathrm{CF}$ composite is lower than that on bare $\mathrm{Cu}$ and adapted with CVD diamond growth. Naturally engineered composite surfaces have enhanced the adhesion of the diamond film on the composite substrate via mechanical interlocking.
\end{abstract}

KEYWORDS: MMC, diamond deposition, combustion CVD, mechanical gripping, surface engineering 


\section{INTRODUCTION}

Diamond exhibits exceptional properties that make it a suitable material for various applications such as coatings for cutting and drilling tools and thermal dissipation. Combustion flame chemical vapor deposition is being used to produce polycrystalline diamond films [1-3]. Its flexibility allows operating in open air and at a low cost, which results in high growth rates.

Diamond depositions have been conducted on several non-diamond substrates showing mainly two issues, low growth rate and poor adhesion. While the growth rate is related to nucleation density [4], the adhesion is compromised because of the internal residual stresses in the deposited diamond films [5]. These stresses are divided in two parts, thermal stress which is provoked by the coefficient of thermal expansion (CTE) mismatch between the diamond film and the substrate, and intrinsic stress which is related to the grain boundary formation and impurity content during diamond growth. As diamond is characterized by a very low CTE, it is often incompatible with conventional non-diamond substrates, such as metals. The thermal stresses in these cases are often compressive and result in the diamond film cracking and eventually peeling off [6-10].

The substantial differences in thermo-mechanical properties of the non-carbon substrates and diamond, makes it difficult to obtain adherent diamond films. Several techniques, such as heat treatments, and chemical and physical etching [11], have been applied to reduce the amounts of residual stresses and therefore prevent delamination. Ali et al. have opted for a carbideforming chromium interlayer to chemically modify the surface and use covalent bonding to make diamond adherent on copper [12]. While a number of studies on the modification of the surfaces either by insertion of carbide forming interlayers [12-13] or by heat treatments and etching have been carried out, there is still very few information on diamond growth on copper surfaces.

The purpose of this work is to investigate diamond deposition on copper/carbon composite materials using combustion flame CVD in open air. Depositions were carried out on a number of composites of different volume fractions of CF. Different volume fractions resulted in different surfaces in terms of carbon content and allowed natural surface engineering to occur. Additionally, theoretical and experimental CTEs have also been investigated. Adherent diamond films were characterized using scanning electron microscopy (SEM) to investigate the surface and cross-sectional morphologies of the films. Raman spectroscopy investigations were carried out to evaluate the phase purity and residual stresses of the diamond films. The SEM 
micrographs have allowed suggesting a growth mechanism of diamond films on copper-based composites. The Raman analyses have shown the dependence of phase purity and residual stresses on the film thickness. It was found that composites containing sufficient amounts of CF were suitable substrates for adherent diamond films.

\section{EXPERIMENTAL DETAILS}

2.1. Copper-based composites. The composite materials consist of a copper matrix and short CF reinforcements. The CF (K223HM, CTN DIALEAD/BOBBINS, Sumitomo Corporation Europe) are pre-grinded to an average length of $200 \mu \mathrm{m}$. Dendritic copper powders (Eckart Granulate Velden $\mathrm{GmbH})\left(\mathrm{d}_{50}\right.$ close to $35 \mu \mathrm{m}$ ) were used as the matrix material.

The sintering of the composite materials has been carried out using a Termolab press. The powders were mixed and compacted in a steel mould heated by an induction system. The powders were pressed at $650{ }^{\circ} \mathrm{C}$ under $40 \mathrm{MPa}$ for $30 \mathrm{~min}$. The temperature is controlled with the use of a thermocouple which is inserted in the steel mould. The chamber is put under vacuum $\left(10^{-2}\right.$ mbar range) to prevent the oxidation of the copper matrix during heating and/or cooling. Composites with 10\%, 20\%, 30\%, $40 \%$ and $50 \%$ volume fractions of CF were densified. The final porosities observed are inferior to $4 \%$ for 10 to $40 \% \mathrm{CF}$, and $7 \%$ for $50 \%$. Furthermore, the CF show no specific degradation. The final outcome is pellets of $40 \mathrm{~mm}$ of diameter and $2 \mathrm{~mm}$ in thickness. The pellets of the composites, up to $40 \%$ volume fraction of $\mathrm{CF}$, were then cut in $6 \times 6 \times 2 \mathrm{~mm}^{3}$ pieces using an ISOMet 1000 precision saw. The optical micrographs of the $\mathrm{Cu} / \mathrm{CF}$ composite materials show a strong anisotropic structure (Figure 1), with the orientation of the CF perpendicular to the compaction direction. This anisotropy is caused by strains and stresses imposed by the processing-induced deformations and geometry, and will be reflected in the anisotropic thermal $(\mathrm{k})$ and thermomechanical (CTE) properties of the composite materials. 

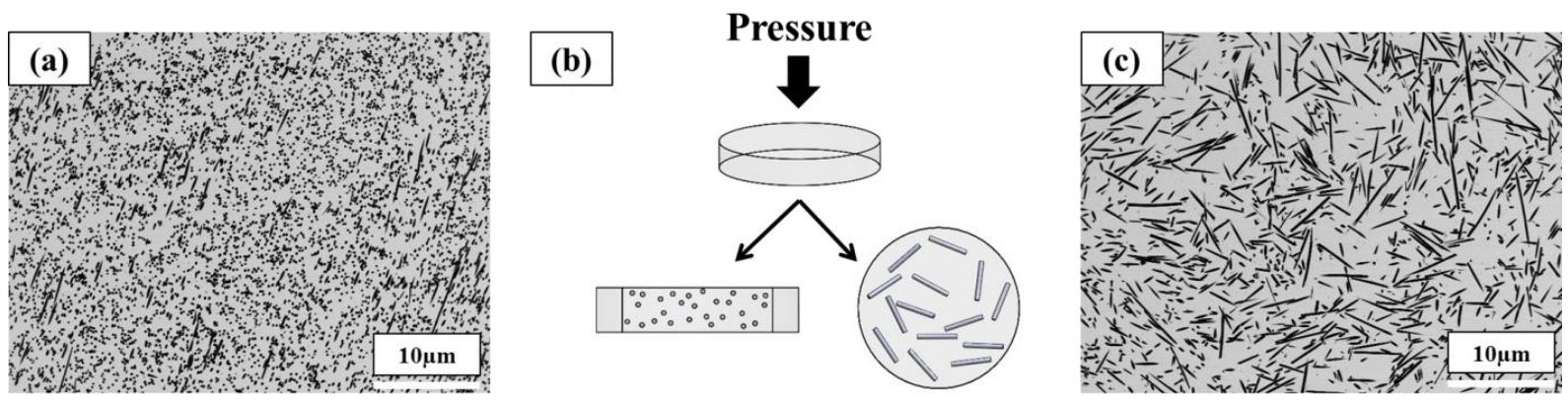

Cross-section Parallel section

Figure 1: Optical micrographs of the composite material (40 vol\% in CF) in (a) cross and (c) parallel section after densification and (b) schematic of the CF orientation

2.2. Combustion flame CVD. The diamond deposition setup consists of a combustion system. The combustion torch, with a diameter of $1.5 \mathrm{~mm}$, delivers a gas mixture of acetylene $\left(\mathrm{C}_{2} \mathrm{H}_{2}, 99.999 \%\right)$, ethylene $\left(\mathrm{C}_{2} \mathrm{H}_{4}, 99.6 \%\right)$ and oxygen $\left(\mathrm{O}_{2}, 99.996 \%\right)$ with a volume ratio of 1:1:2 respectively. The distance between the inner flame cone and the top of the substrate was maintained at $1.5 \mathrm{~mm}$. The substrates were positioned using an $\mathrm{X}-\mathrm{Y}-\mathrm{Z}$ moving stage. A cooling system below the stage is used to regulate the deposition temperature. Unlike diamond depositions on Si and WC substrates [8], the temperature was kept between 710 and $740{ }^{\circ} \mathrm{C}$. The substrate temperature was monitored using an infrared pyrometer (OS3752, Omega Engineering, Inc.).

2.3. Diamond film characterization. The microstructure and cross-section of the deposited diamond films have been evaluated using scanning electron microscopy (XL-30, Philips Electronics). The cross-sections were polished using Argon ion milling (Gatan Model 693, Ilion+) for 4 hours under $5 \mathrm{kV}$. Raman spectroscopic analyses have been carried out using a micro-Raman spectrometer (Renishaw inVia H18415) with a $514.5 \mathrm{~nm}$ laser excitation.

2.4. CTE measurement and simulations. Thermo-mechanical simulations were also carried out to evaluate the impact of the diamond film on the surface of a $\mathrm{Cu} / \mathrm{CF}$ composite, on heat dissipation through the substrate. A volume fraction of $40 \%$ vol of CF was selected for the simulations. Two geometries were used: one where the several heat sources (simulated silicon chips) are placed on the surface of the $\mathrm{Cu} / \mathrm{CF}$ composite and one where the heat sources are placed on a diamond film- $\mathrm{Cu} / \mathrm{CF}$ assembly. The $\mathrm{Cu} / \mathrm{CF}$ substrate and diamond film thickness are set as $2 \mathrm{~mm}$ and $100 \mu \mathrm{m}$ respectively. 
Thermal expansion coefficients along the fibers direction were measured on all samples of the same dimensions using a horizontal Netzsch dilatometer DIL402C. The device was calibrated using an alumina sample.

The COMSOL software makes it possible to predict the thermo-mechanical behavior of an electronic assembly. The temperature distribution used for the thermomechanical analyses is directly available from the COMSOL heat transfer module. The model developed for these simulations consists of a copper matrix composite reinforced with anisotropic CF. The aspect ratio of the $\mathrm{CF}$ (diameter/length $=10 / 200=0.05)$ is respected and different volume fractions of CF were analyzed: $10 \%, 20 \%, 30 \%, 40 \%$ and $50 \%$. A parametric study was done with a parameter angle ranging from 0 to $90^{\circ}$. An average value of the displacement of the composite for all the angles was taken for the CTE calculations. In order to add anisotropic properties to the $\mathrm{CF}$, according to the different angles, a second rotated coordinate system is added. This rotated system is also parameterized with the parameter angle.

The governing equations consist of the Fourier heat transfer equation. The stationary state heat transfer equation is [6]:

$-\nabla \cdot(k \nabla T)=Q$

where $T$ is the temperature, $k$ the thermal conductivity and $Q$ the heat source. The boundary conditions for heat flux are defined as follows:

$n \cdot(k \nabla T)=h\left(T_{\text {ext }}-T\right)$

where $n$ is the normal vector to the boundary, $h$ is the heat transfer coefficient and $T_{\text {ext }}$ the external (ambient) temperature. The elastic equation including the thermal expansion of materials is represented in the following relationship:

$-\nabla \cdot(c \nabla u+a T)=K$,

where $c$ is the stiffness of the matrix, $u$ is the deformation of the matrix, $a$ is the coefficient of thermal expansion and $K$ the volume forces. All materials' data, as the Young modulus (E), Poisson ratio (v), CTE, density (d) and materials size ( $\mathrm{Cu}$ particles and short $\mathrm{CF})$ are given in Table 1. 
Table 1: Thermal and mechanical properties of copper and CF materials at $140{ }^{\circ} \mathrm{C}$ (calculation temperature)

\begin{tabular}{lll}
\hline & $\begin{array}{l}\text { Cu Powder } \\
\text { Isotropic } \\
\text { Material Data }\end{array}$ & $\begin{array}{l}\text { Carbon Fiber } \\
\text { Orthotropic }(\mathbf{x}, \mathbf{y}, \mathbf{z}) \\
\end{array}$ \\
& Velden $\mathrm{GmbH})$ & (Sumitomo \\
& 35 & 25 \\
\hline $\mathrm{l}(\mathrm{mm})$ & 35 & 1 \\
$\mathrm{~L}(\mu \mathrm{m})$ & 17 & $(-1,12,12)$ \\
$\mathrm{CTE}\left(10^{-6} / \mathrm{K}\right)$ & 110 & $(780,15,15)$ \\
$\mathrm{E}(\mathrm{GPa})$ & 0.34 & $(0.2,0.2,0.2)$ \\
$v$ & 8900 & 2200 \\
$\mathrm{~d}\left(\mathrm{~kg} / \mathrm{m}^{3}\right)$ & & \\
\hline
\end{tabular}

\section{RESULTS AND DISCUSSIONS}

3.1. Interest of diamond film/composite assemblies. The impact of the diamond film on heat dissipation has been simulated in order to predict the behavior of the diamond film- $\mathrm{Cu} / \mathrm{CF}$ assemblies. The temperature profiles through $\mathrm{Cu} / \mathrm{CF} 40 \%$ vol substrates without and with diamond coating are reported in Figure 2 (a) and (b) respectively. Several heat sources are integrated on the same heat-sink. One can observe that the isovalue lines of temperature are clearly shifted due to the planar heat-spreading induced by the diamond coating in the case of the diamond film/composite assembly. This planar heat spreading at the surface of heat sink leads to the increase of heat dissipation by conduction through the substrate, but also by convection on the substrate surface, in particular close to the heat sources. The latter mode can have a large impact, in particular when the heat source sizes are small and the substrate is thick. 
(a)

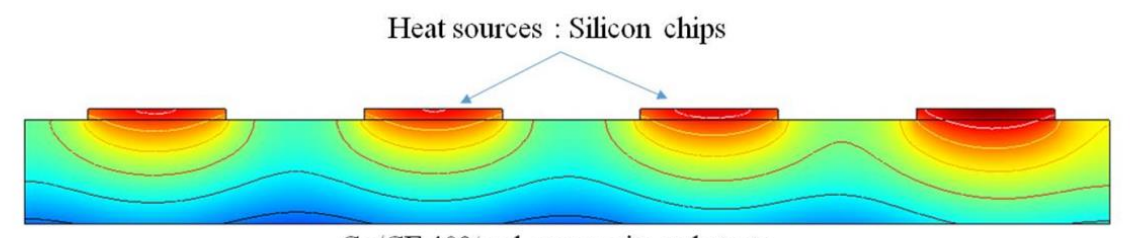

With diamond coating

$\mathrm{Cu} / \mathrm{CF} 40 \%$ vol composite substrate $(\mathrm{e}=100 \mu \mathrm{m})$

(b)

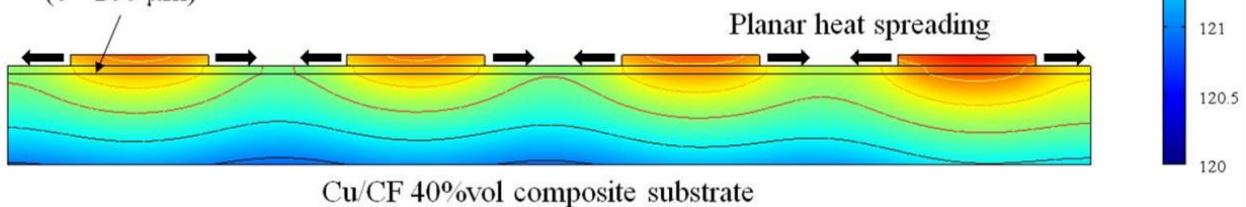

Figure 2: Simulation of heat-dissipation of $\mathrm{Cu} / \mathrm{CF} 40 \%$ substrate and diamond film-Cu/CF $40 \%$ substrate

3.2. Effect of the reinforcement volume fraction on the CTEs. The CTEs of the $\mathrm{Cu} / \mathrm{CF}$ composite materials have been calculated and measured for composite materials containing different volume fractions of $\mathrm{CF}$. Both calculations and measurements show the decrease of the CTEs with increasing CF content. However, there is a substantial difference between the theoretical and experimental values. For a volume fraction of CF lower than $30 \%$ the measured CTEs are higher than the calculated ones whereas for volume fraction of CF higher than $30 \%$ the measured CTEs are lower than the calculated ones. 


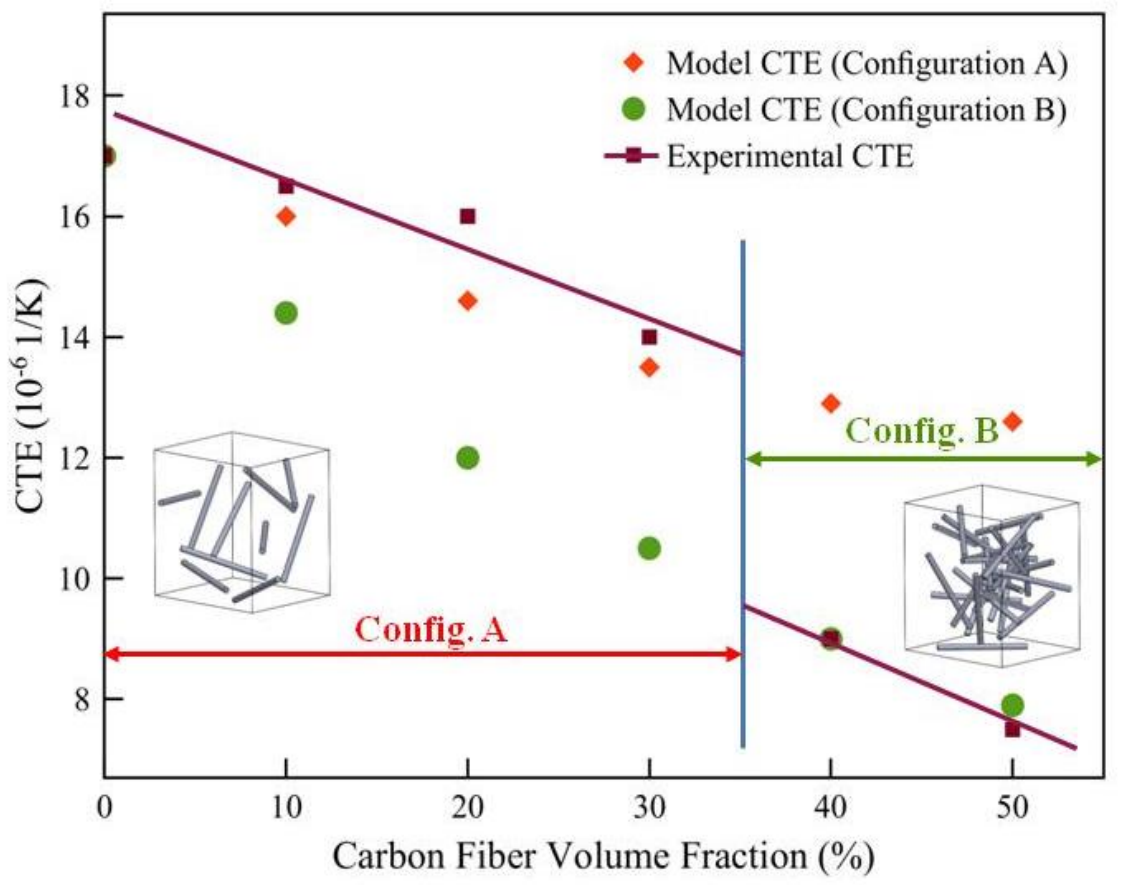

Figure 3: Comparison of theoretical and experimental CTE values for a $\mathrm{Cu} / \mathrm{CF}$ composite of $\mathrm{CF}$ volume fractions from $0-50 \%$ - Schematic theoretical configurations of $\mathrm{CF}$ in the $\mathrm{Cu}$ matrix. Configuration A: randomly distributed CF with no inter-fiber contacts and, Configuration B: randomly distributed $\mathrm{CF}$ with inter-fiber contacts - creation of rigid preform

The experimental and theoretical values of CTEs for different configurations of CF inside the matrix are given in Figure 3Erreur ! Source du renvoi introuvable.. Configuration A corresponds to randomly distributed CF with no contact between them and configuration B is related to homogeneously distributed fibers with contact points between them, which create a rigid preform. From the graph it appears that configurations A is in agreement of the experimental values for volume fractions that are equal or inferior to $30 \%$. For 40 vol\% and more of $\mathrm{CF}$, configuration $\mathrm{A}$ is no longer representative of the experimental values. At this point, configuration B seems to follow the right trend, therefore fiber-fiber interactions must be taken into account. The fiber intertwining induces the creation of a rigid preform and causes the drastic change in the CTE values. One can conclude that the percolation threshold for the type of fiber considered in this investigation is situated between 30 and 40 vol\% of CF.

Figure 4 shows the simulation results obtained for diamond film/ $\mathrm{Cu}$ and diamond film- $\mathrm{Cu} / \mathrm{CF}$ $40 \%$ vol assemblies. To illustrate the positive effect of the composite material on residual stresses generated in the film because of the CTE mismatch, both assemblies were heated to $740{ }^{\circ} \mathrm{C}$, which is the temperature at which the combustion CVD process takes place, and cooled 
to room temperature. One can observe the profile of normal stresses in the planar direction of the assemblies. The diamond coating is under compressive stresses (negative values) when on top of both $\mathrm{Cu}$ and the $\mathrm{Cu} / \mathrm{CF}$ composite. However, one can notice a decrease of the compressive stresses of 3 to 4 times in the case of the composite. Therefore, the interest of using composite substrates rather than $\mathrm{Cu}$, is clearly demonstrated.

(a)

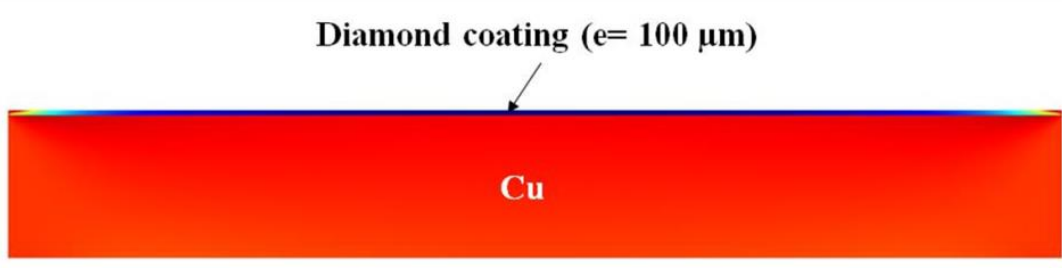

(b)

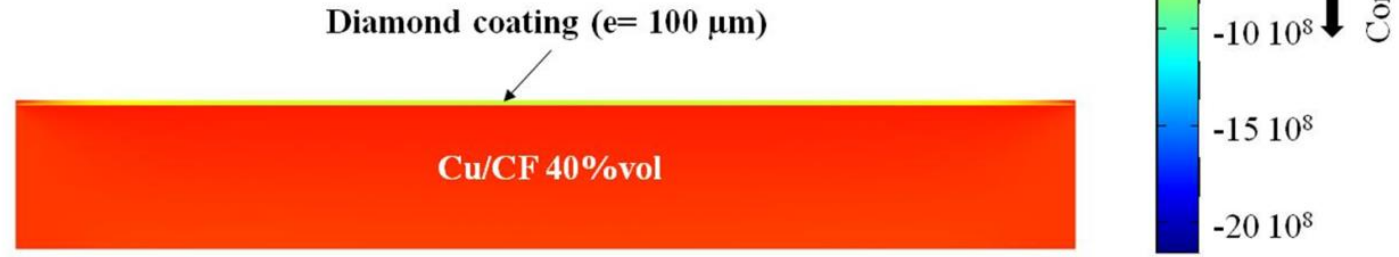

Figure 4: Simulated diamond film- $\mathrm{Cu}$ and diamond film-Cu/CF $40 \%$ assemblies at room temperature. The simulation shows the residual stresses in the diamond films after cooling from $700^{\circ} \mathrm{C}$

3.3. First moments of diamond deposition. The SEM micrographs of a $\mathrm{Cu} / \mathrm{CF} 40 \mathrm{vol} \%$ composite before diamond deposition and after 2, 5, and $15 \mathrm{~min}$ of diamond deposition, are given in Figure 5. The initial surface shows the preferential orientation of the fibers which is perpendicular to the compression axis, leading to a random distribution of $\mathrm{CF}$ in that plane (Figure 5 (a)). Naturally engineering surfaces occur because combustion CVD is operated in open air and at high temperature, which results in the consumption of the exposed CF. In fact, operating in open air and at a high concentration of $\mathrm{O}_{2}$ causes the $\mathrm{CF}$ to burn and leave fibershaped voids on the surface. It is important to note that the CF that are consumed need to be exposed to the combustion flame. The consumption of the CF starts after 2 min (Figure 5, (b)) of diamond deposition. By 5 min (Figure 5, (c)), the fibers have been completely consumed, leaving fiber-shaped voids. Depending on the depth at which the CF are situated, with respect to the surface (maximum $10 \mu \mathrm{m}$ ), the voids will either be open or closed (Figure 6). Such voids can act as mechanical gripping sites of the diamond film on the composite substrates [11, 14]. By the end of the 15 min of diamond deposition (Figure 5, (d)), a mixture of $\mathrm{sp}^{2}$ and $\mathrm{sp}^{3}$ carbon is observed on the surface with a predominance of $\mathrm{sp}^{2}$ carbon. The predominance of $\mathrm{sp}^{2}$ carbon 
has been confirmed through Raman analyses carried out on the cross-sections of the diamond films, close to the $\mathrm{Cu} / \mathrm{CF}$-diamond interface.
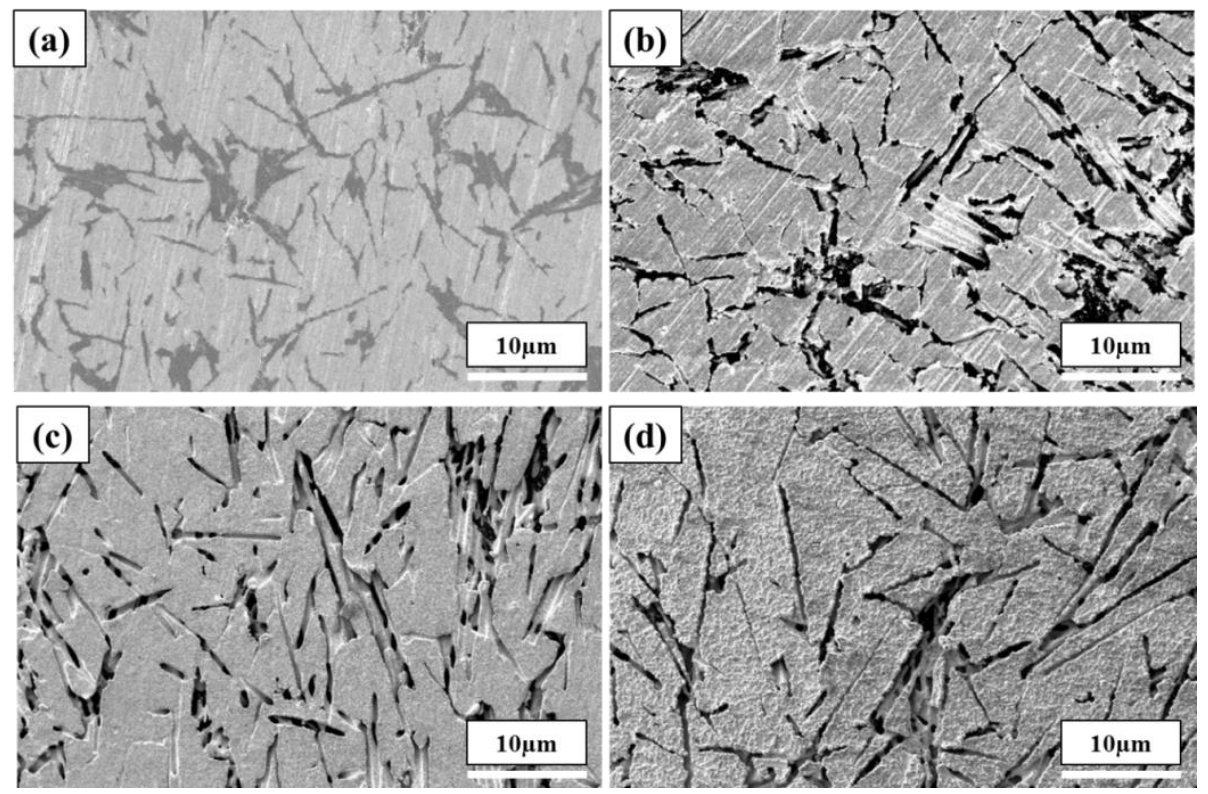

Figure 5: $\mathrm{Cu} / \mathrm{CF} 40$ vol\% surface (a) before diamond deposition, (b) after $2 \mathrm{~min}$, (c) after 5 min, and (d) after 15 min of diamond deposition

(a)

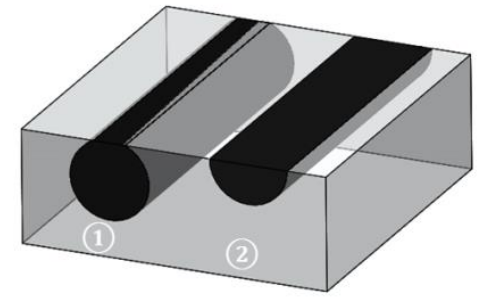

(b)

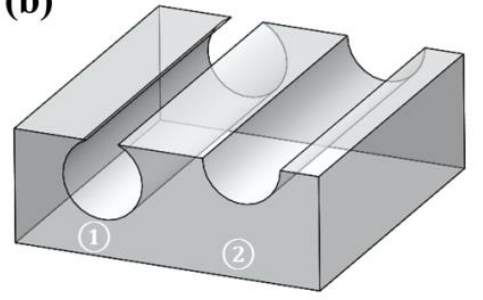

Figure 6: Schematic view of the initial surface and the voids left on the surface after the CF consumption. (a) Before diamond deposition, (b) (1) closed void (the gap of the void is sufficiently small to trap deposited carbon) and (b) (2) open void (the gap of the void is large enough that it cannot trap carbon), after diamond deposition.

Longer diamond depositions were carried out on $10 \%, 20 \%, 30 \%$ and $40 \%$ vol $\mathrm{Cu} / \mathrm{CF}$ composites until a detachment of the diamond film had been observed. The diamond films easily peel off from the low CF content composites, and remain attached on the surface of the high content in $\mathrm{CF}$ composites ( $\mathrm{Cu} / \mathrm{CF} 40$ vol\%). SEM micrographs of the bottom face of a peeled-off diamond film and the surface of a $\mathrm{Cu} / \mathrm{CF} 20$ vol\% composite are shown in Figure 7 (a) and (b) respectively. The micrographs confirm the initial growth of a diamond-like carbon 
film, as shown in one of our earlier studies [15], and show protrusions of ball-like carbon that exceed the surface. The presence of ball-like carbon inside the voids on the upper surface of the composites confirms the initial growth of carbon within the voids, and therefore the enhancement of mechanical gripping.
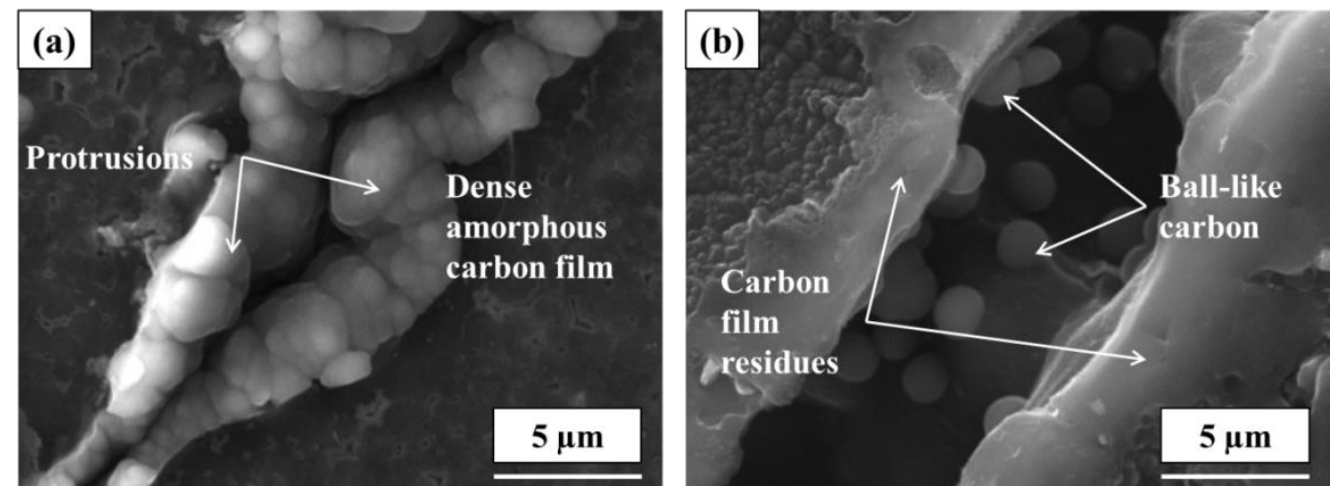

Figure 7: SEM micrographs of (a) a bottom face of diamond film with ball-like carbon protrusions and (b) surface of a $\mathrm{Cu} / \mathrm{CF} 20$ vol\% composite after diamond film peel-off

3.4. Microstructure of the diamond films. SEM micrographs of the cross-sections and surfaces of diamond films deposited on $\mathrm{Cu} / \mathrm{CF} 40$ vol\% substrates for different durations are shown in Figure 8. Diamond films were deposited on the substrates as circular spots of approximately $1 \mathrm{~cm}$ in diameter for $90,120,180$, and $240 \mathrm{~min}$. The combustion flame deposition has enabled the deposition of resisting diamond films of different thicknesses depending on time. The adhesion of the films is explained by both the decreased CTE of the $\mathrm{Cu} / \mathrm{CF} 40 \%$ composite and the large amounts of fiber-shaped voids on the surface. Indeed, the composites with $40 \mathrm{vol} \%$ of CF indicate the presence of a larger amount of fibers exposed on the surface.

The films obtained are dense polycrystalline films and consist of randomly oriented diamond crystals. The growth rates were equivalent for all substrates and were about $0.12 \mu \mathrm{m} / \mathrm{min}$. According to the cross-sectional SEM micrographs of the diamond films deposited during 90, 120, 180, and 240 min, shown in Figure 8, the growth is columnar. This indicates that the majority of diamond crystals grow along the <111> direction, hence exposing (100) faces on the surface, and that the facet velocity growth ratio is close to 1 [16]. The cross-sectional observations have confirmed the hypothesis made on columnar morphology deduced from the facet velocity ratio. It appears that the diamond growth follows the Volmer-Weber [17] mode which involves the 3D growth of germs. First the nucleation of carbon germs (mixture of $\mathrm{sp}^{2}$ and $\mathrm{sp}^{3}$ ) on the surface takes place, then they grow in 3D and finally, they coalesce to form a 
continuous film. The columnar microstructure is therefore obtained. Table 2 gathers the grain size and film thickness comparison for each diamond deposition.
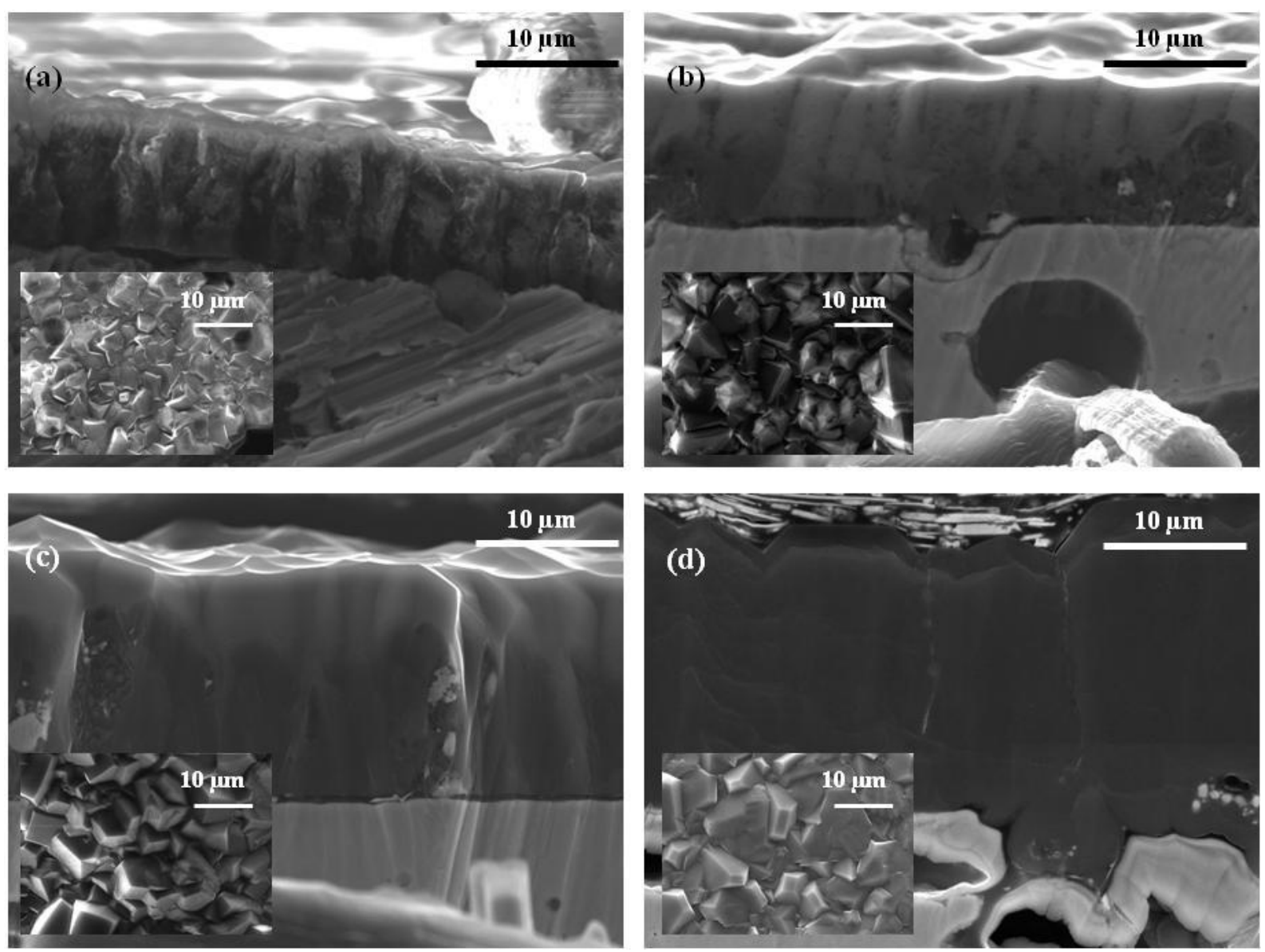

Figure 8: SEM micrographs the surface and cross-section of diamond films deposited on $\mathrm{Cu} / \mathrm{CF} 40 \%$ composite materials using combustion flame CVD for (a) $t=90$ min, (b) $t=120$ $\min ,(c t=180 \mathrm{~min}$, and $(\mathrm{d}) \mathrm{t}=240 \mathrm{~min}$.

3.5. Raman Spectroscopic Investigations. The Raman spectra were analyzed by multiGaussian peak fitting using three peaks at, $\sim 1332, \sim 1350$, and $\sim 1500 \mathrm{~cm}^{-1}$ as seen in Figure 9Erreur ! Source du renvoi introuvable.. Stress-free diamond peaks are usually situated at 1332 $\mathrm{cm}^{-1}$ in the literature, however, in the case of the copper-based substrates; thermomechanical stresses at the substrate-film interface cause the peaks to shift to higher wavenumbers.

Figure 10 shows the comparison of the Raman spectra of diamond films being deposited on $\mathrm{Cu} / \mathrm{CF} 40 \%$ composites at 90, 120, 180, and $240 \mathrm{~min}$. All the analyzed spectra exhibit sharp diamond peaks located at around $1332 \mathrm{~cm}^{-1}$. The D-band $\left(1375 \mathrm{~cm}^{-1}\right)$ and the graphitic carbon broad band ([1500-1580] $\left.\mathrm{cm}^{-1}\right)$ show decreasing intensities with increasing deposition times. 
This indicates the decrease of $\mathrm{sp}^{2} / \mathrm{sp}^{3}$ carbon ratio in the film, and therefore the phase purity enhancement with increasing film thickness.

The diamond phase purity was quantified through the calculation of the diamond quality factor, using the equation below [18]:

$Q_{514 n m}=\frac{I_{\text {Diamond }}}{\left(I_{\text {Diamond }}+\frac{I_{a-\text { carbon }}}{233}\right)} 100(\%)$

where $I_{\text {Diamond }}$ is the intensity of the diamond peak and $I_{a \text {-carbon }}$ is the sum of the intensities observed for non-diamond carbon. The values of the quality factor are superior to $85 \%$ and reach $95 \%$ in the case of $240 \mathrm{~min}$ long diamond depositions. This was ascribed to the fact that with increasing deposition durations and therefore thicknesses, the films tend to grow with less non-diamond carbon trapped. Indeed, as the thickness increases, the diamond grain size increases as well and there are therefore less grain boundaries. Since amorphous carbon and impurities tend to locate at the grain boundaries, the overall quality of the diamond film is improved when the amount of grain boundaries decreases.

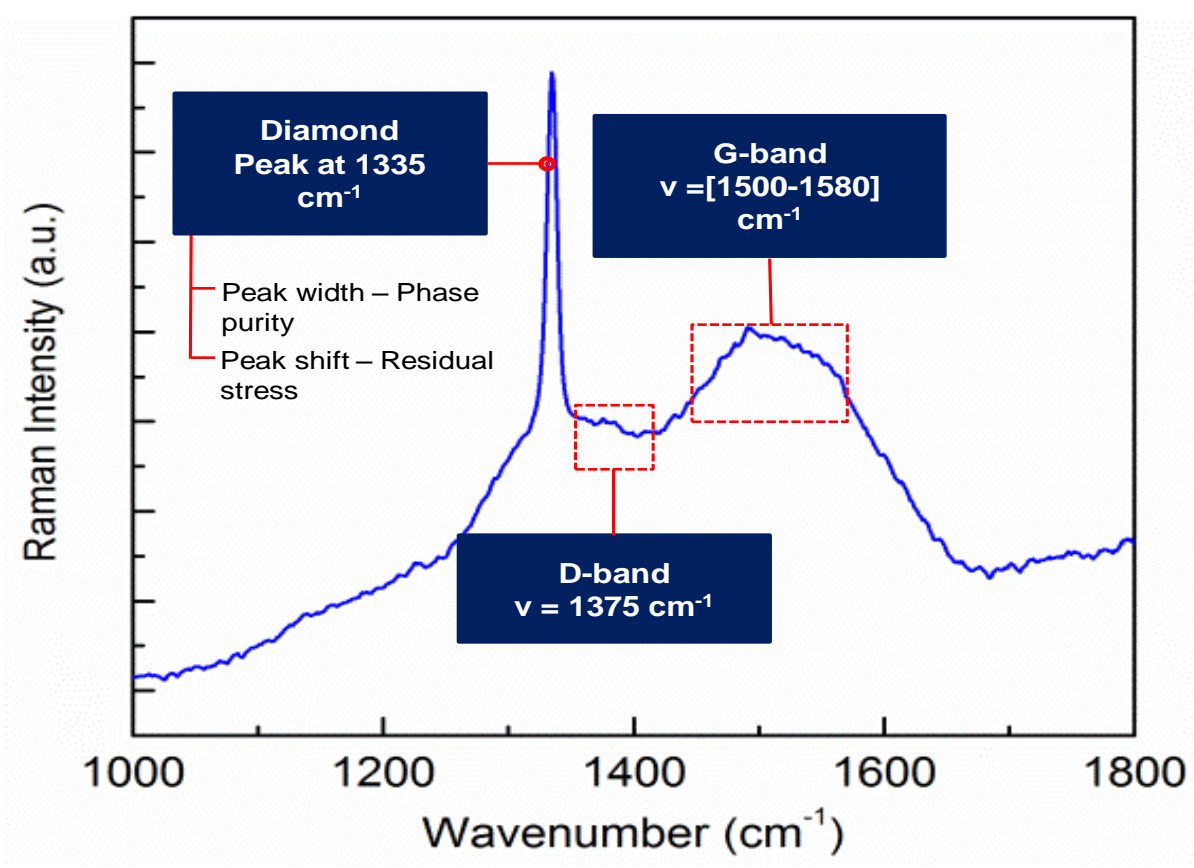

Figure 9: Typical Raman spectra of a diamond film deposited on a $\mathrm{Cu} / \mathrm{CF}$ composite. 


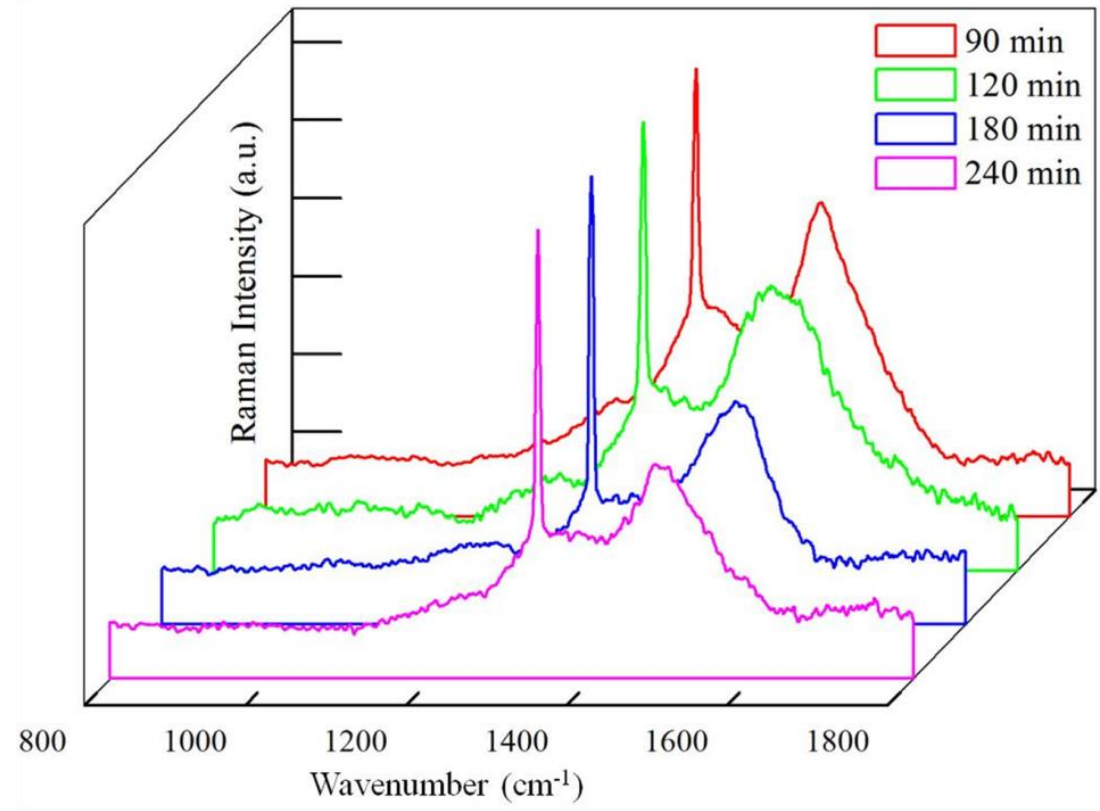

Figure 10: Raman spectra of diamond films deposited on $\mathrm{Cu} / \mathrm{CF} 40 \%$ composites during 90, 120,180 , and $240 \mathrm{~min}$

Residual stresses gather thermal stress induced by the thermal expansion mismatch between the diamond film, the substrate and intrinsic stress, which is related to the growth of the diamond film. The stresses are quantified as follows [8]:

$\sigma=0.567\left(v_{m}-v_{0}\right)$

where $v_{m}$ and $v_{0}$ are the observed Raman peak positions of stressed and unstressed $\left(1332 \mathrm{~cm}^{-}\right.$ $\left.{ }^{1}\right)$ diamond respectively. Diamond films of different thicknesses have shown peak shifts to higher wave numbers compared to stress-free diamond films. These peak shifts indicate the presence of compressive stresses in the film. The peak shift however is less important as the diamond film thickness increases. While for 90 and $120 \mathrm{~min}$ of diamond depositions the diamond peak is situated close to $1334.6 \mathrm{~cm}^{-1}$, longer deposition times show a decrease of the shift to $1333 \mathrm{~cm}^{-1}$. The overall residual stresses are therefore decreased to less than $1 \mathrm{GPa}$ in the diamond film obtained after $240 \mathrm{~min}$ of deposition. The decrease of the compressive residual stresses is related to the increase of the tensile stresses (intrinsic stress). One can conclude that after a certain thickness the growth mode of the diamond film is more influent on the residual stresses than thermal mismatch. Therefore, the CTE has been sufficiently decreased. Quality factors and residual stresses are given in Table 2. 
Table 2: Comparison of grain size, film thickness, quality factor and residual stresses of diamond films deposited during 90, 120, 180, and $240 \mathrm{~min}$

\begin{tabular}{lllll}
\hline Deposition Time $(\mathbf{m i n})$ & $\mathbf{9 0}$ & $\mathbf{1 2 0}$ & $\mathbf{1 8 0}$ & $\mathbf{2 4 0}$ \\
\hline Grain Size $(\boldsymbol{\mu m})$ & 2.50 & 3.79 & 5.85 & 8.09 \\
Film Thickness $(\boldsymbol{\mu m})$ & 9.39 & 16.74 & 22.38 & 25.41 \\
Quality factor $(\boldsymbol{\%})$ & 83.4 & 91.7 & 92.1 & 95.1 \\
Residual stresses $(\mathbf{G P a})$ & -1.48 & -1.25 & -1.21 & -0.62 \\
\hline
\end{tabular}

\section{CONCLUSION}

High content CF materials have been successfully coated with resisting diamond films in open air using combustion flame CVD. SEM micrographs showed dense polycrystalline diamond films consisting of faceted diamond crystals. Raman spectroscopy shed light on the increase of the phase purity with increasing diamond film thickness which is related to larger diamond grains. Also, it revealed the decrease of total residual stresses with increasing thickness, indicating hence the increase of intrinsic tensile stresses during diamond growth. The insertion of CF brings good assets to the copper-based substrates. They allow tailoring the substrate's CTE and hence induce a decrease in thermally induced stresses at the diamond/substrate interface. The accordance between theoretical and experimental CTE values has been shown, as well as the necessity to take into account the formation of a rigid preform due to inter-fiber contacts. The $\mathrm{CF}$ also bring additional roughness to the surface, due to their consumption, which increases the possibility of mechanical gripping and the amount of reactive sites. The initial deposition of an amorphous carbon layer prior to diamond growth is confirmed. The growth mechanism of diamond films on $\mathrm{Cu} / \mathrm{CF}$ composites is following the Volmer-Weber model.

\section{- AUTHOR INFORMATION}

Corresponding Authors

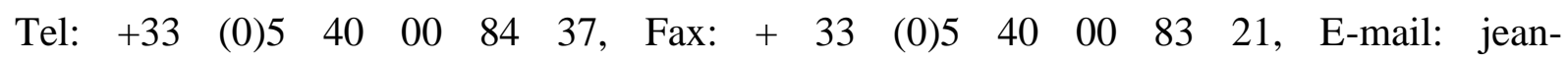
francois.silvain@icmcb.cnrs.fr

Tel: +1-402-472-8323, Fax: +1-472-4732, E-mail: ylu2@unl.edu

\section{- AKNOWLEDGEMENT}


The authors thank Dr. D. R. Alexander in the Department of Electrical and Computer Engineering at the University of Nebraska-Lincoln for providing convenient access to the SEM, and the Plateforme Aquitaine de Caractérisation des Matériaux in Bordeaux, France for providing access to the Argon-ion milling apparatus.

\section{- REFERENCES}

[1] M. Murakawa, S. Takeuchi, Y. Hirose, Surf. \& Coat. Tech., 43/44 (1990) 22-29

[2] J. B. Donnet, H. Oulanti, T. Le Huu, M. Schmitt, Carbon, 44 (2006) 374-380

[3] M. Murakawa, S. Takeuchi, Y. Hirose, Surf. \& Coat. Tech., 39/40 (1989) 235-240

[4] R. Shima-Edelstein, I. Gouzman, A. Hoffman, Israel Journal of Chemistry, 38 (1998) 1731

[5] C. Li, H. Li, D. Niu, F. Lu, W. Tang, G. Chen, H. Zhou, F. Chen, Surf. \& Coat. Tech., 201 (2007) 6553-6556

[6] P.M. Geffroy, J.D. Mathias, J.F. Silvain, Adv. Engineer. Mat., 10 (4), (2008) 400-405

[7] C.T. Kuo, C.R. Lin, H.M. Lien, Thin solid films, 290/291 (1996) 254-259

[8] Q.H. Fan, J. Gracio, E. Pereira, Diamond and Related Material, 9 (2000) 1739-1743

[9] T. Guillemet, Z.Q. Xie, Y.S. Zhou, J.B. Park, A. Veillere, W. Xiong, J.M. Heintz, J.F. Silvain, N. Chandra, Y.F. Lu, ACS Appl. Mater. Interfaces, 3 (2011) 4120-4125

[10] Y. Nakamura, S. Sakagami, Y. Amamoto, Y. Watanabe, Thin Solid Films, 308/309 (1997) 294-253

[11] A. Veillère, T. Guillemet, Z.Q. Xie, C. A. Zuhlke, D. R. Alexander, J.F. Silvain, J.M. Heintz, N. Chandra, Y.F. Lu, ACS Appl. Mater. Interfaces, 3 (2011) 1134-1139

[12] Ali, N.; Ahmed, W.; Rego, C. a. \& Fan, Q. H., Diamond and Related Materials, 9 (2000), 1464-1470

[13] Q. H. Fan, A. Fernandes, E. Pereira, J. Gracio, Vacuum, 52 (1999) 193-198 
[14] M. Chandran, C. R. Kumaran, S. Vijayan, S.S. Bhattacharya, M.S. Ramachandra Rao, Mater. Express, 2 (2012) 115-120

[15] Y.X. Han, M. Zhao, J. Sun, H. Ling, T. Gebre, Y.F. Lu, Appl. Surf. Science, 254 (2007) $1423-1426$

[16] P. Smereka, X. Li, G. Russo, D.J. Srolovitz, Acta Materialia, 53 (2005) 1191-1204

[17] V. Elofsson, D. Magnfält, P. Münger and K. Sarakinos, Journal of Applied Physics, 116 (2014) No. 4, 044302

[18] G.W. Bak, K. Fabisiak, L. Klimek, M. Koznecki, E. Staryga, Optical Materials, 30 (2008) $770-773$ 